University of Nebraska - Lincoln

DigitalCommons@University of Nebraska - Lincoln

2012

\title{
Assessment of the in vivo genotoxicity of isomers of dinitrotoluene using the alkaline Comet and peripheral blood micronucleus assays
}

\author{
Emily May Lent \\ US Army Public Health Command, emily.m.lent@us.army.mil \\ Lee C.B. Crouse \\ US Army Public Health Command \\ Michael J. Quinn Jr \\ US Army Public Health Command \\ Shannon M. Wallace \\ US Army Public Health Command
}

Follow this and additional works at: https://digitalcommons.unl.edu/usarmyresearch

Lent, Emily May; Crouse, Lee C.B.; Quinn, Michael J. Jr; and Wallace, Shannon M., "Assessment of the in vivo genotoxicity of isomers of dinitrotoluene using the alkaline Comet and peripheral blood micronucleus assays" (2012). US Army Research. 204.

https://digitalcommons.unl.edu/usarmyresearch/204

This Article is brought to you for free and open access by the U.S. Department of Defense at DigitalCommons@University of Nebraska - Lincoln. It has been accepted for inclusion in US Army Research by an authorized administrator of DigitalCommons@University of Nebraska - Lincoln. 


\title{
Mutation Research/Genetic Toxicology and Environmental Mutagenesis
}

\section{Assessment of the in vivo genotoxicity of isomers of dinitrotoluene using the alkaline Comet and peripheral blood micronucleus assays}

\author{
Emily May Lent*, Lee C.B. Crouse, Michael J. Quinn Jr, Shannon M. Wallace \\ US Army Public Health Command, Toxicology Portfolio, 5158 Blackhawk Road, Aberdeen Proving Ground, MD 21050, USA
}

\section{A R T I C L E I N F O}

\section{Article history:}

Received 25 August 2011

Received in revised form

23 November 2011

Accepted 24 November 2011

Available online 6 December 2011

\section{Keywords:}

Peripheral blood micronucleus assay

Comet assay

Dinitrotoluene

Genotoxicity

\begin{abstract}
A B S T R A C T
Dinitrotoluene (DNT) is a nitroaromatic explosive that exists as six isomers; two major isomers (2,4- and 2,6-DNT) and four minor isomers (2,3-, 2,5-, 3,4-, and 3,5-DNT). DNT has been found in soil, surface water, and groundwater near ammunition production plants. The major isomers of DNT are classified as "likely to cause cancer in humans." In vitro studies have provided conflicting data regarding the genotoxicity of the minor isomers. Studies indicate that metabolism in the gut and liver are necessary to convert DNT to genotoxic compounds. As such, in the present study the genotoxicity of isomers of DNT was assessed using two in vivo genotoxicity assays. The Comet assay was used to detect DNA damage in liver cells from male Sprague-Dawley rats following oral exposure (14-day) to individual isomers of DNT. The micronucleus assay was conducted using flow cytometric analysis to detect chromosomal damage in peripheral blood. Treatment with 2,3-, 3,4-, 2,4-, 2,5- and 3,5-DNT did not induce DNA damage in liver cells or increase the frequency of micronucleated reticulocytes (MN-RET) in peripheral blood at the doses tested. Treatment with 2,6-DNT induced DNA damage in liver tissue at all doses tested, but did not increase the frequency of micronucleated reticulocytes (MN-RET) in peripheral blood. Thus, 2,4-DNT and the minor isomers were not genotoxic under these test conditions, while 2,6-DNT was genotoxic in the target tissue, the liver. These results support previous research which indicated that the hepatocarcinogenicity of technical grade DNT (TG-DNT) could be attributed to the 2,6-DNT isomer.
\end{abstract}

Published by Elsevier B.V.

\section{Introduction}

Dinitrotoluene (DNT) is used to make polyurethane foams, dyes, and explosives and ammunition. Technical grade DNT (TG-DNT), is composed of approximately 76.5\% 2,4-DNT, 18.8\% 2,6-DNT, and $4.7 \%$ minor isomers (2.43\% 3,4-DNT, $1.54 \%$ 2,3-DNT, $0.69 \%$ 2,5-DNT, and $0.04 \% 3,5-D N T)$. DNTs are common soil contaminants at munitions manufacturing sites, entering the environment as a result of spills occurring during manufacturing processes, open burning/incineration, seepage from landfills and wastewater holding facilities, and leaking of buried ammunition wastes [1,2]. Although DNT entering the environment is largely comprised of the major isomers (2,4-, 2,6-DNT), the minor isomers (2,3-, 2,5-, 3,4-, and 3,5 -DNT) have also been found in the soil and water around Army installations.

The major isomers are listed by the US Environmental Protection Agency (USEPA) as probable human carcinogens based on cancer bioassays conducted with mixtures of DNT isomers. Although two of the three cancer bioassays determined that 2,4-/2,6-DNT and TG-DNT were hepatocarcinogenic in rats $[3,4]$, the third study

\footnotetext{
* Corresponding author. Tel.: +1 410436 7749; fax: +1 4104366710

E-mail address: emily.m.lent@us.army.mil (E.M. Lent).
}

found that 2,4-/2,6-DNT was not an hepatocarcinogen [5]. The differences in carcinogenic effects reported in these studies have been attributed to differences in the mixtures of DNT isomers used (TGDNT vs. 98\% and 95\% 2,4-DNT, respectively), prompting a series of investigations on the carcinogenic potential of the individual isomers. In vivo initiation-promotion assays demonstrated 2,6-DNT to be a complete hepatocarcinogen and showed only weak promoting activity for 2,4-DNT [6-8]. In a one-year study, pure 2,4-DNT was shown to be non-carcinogenic and the cancer rate in rats given TG-DNT was approximately half that of 2,6-DNT, suggesting that not only is 2,6-DNT likely the carcinogenic isomer, but that the other isomers may compete with 2,6-DNT in the metabolic process that produces the active metabolite responsible for the cancer [9]. Although considerable research focused on the major isomers, limited data is available for the minor isomers.

Although bacterial mutagenicity studies have shown the minor isomers to be mutagenic in several strains of bacteria (TA98, TA1538, TA100, and TM677) [10-13], the minor isomers were not genotoxic and did not induce morphological transformation in in vitro assays in mammalian cells (CHO/HPGRT, SHE) $[14,15]$. Treatment of primary rat hepatocyte cultures with the individual minor isomers also did not result in an increase in unscheduled DNA synthesis (UDS), indicating that the minor isomers do not induce increases in DNA damage/repair in the target organ [16]. All of this 
work, however, was conducted in vitro and is likely not reflective of the genotoxicity or carcinogenic potential of these compounds as in vitro assays have been labeled as not predictive of carcinogenicity for this class of chemicals [17]. DNTs and other nitroaromatic compounds are metabolically activated through nitroreduction and oxidative pathways in the liver and the gut $[18,19]$, making in vivo assessments necessary. An in vivo investigation of the ability of DNTs to initiate liver cancer demonstrated that the minor isomers do not increase the altered foci that precede development of neoplasms and carcinomas [7]. In vivo assessments of the genotoxicity of the minor isomers are lacking.

To evaluate the in vivo genotoxicity of the individual isomers of DNT, the peripheral blood micronucleus assay and the liver Comet assay were conducted. Tissues for the assays were collected from animals administered pure isomers of DNT for 14-days in a repeated dose oral toxicity study.

\section{Materials and methods}

These studies were conducted at the US Army Public Health Command in compliance with Good Laboratory Practice standards as described in Title 40, Code of Federal Regulations (CFR), Part 792.

\subsection{Materials}

\subsubsection{Test substances}

Neat 2,4-DNT (CAS \# 121-14-2; lot\#03718EH; purity 99.0\%), 2,3-DNT (CAS \# 602-01-7; lot\#04918JQ; purity 99.9\%), 3,4-DNT (CAS \# 610-39-9; lot\#05713CA; purity 99.9\%), and 2,6-DNT (CAS \# 606-20-2; lot\#08328CR; purity 99.8\%) were purchased from Sigma-Aldrich, 3050 Spruce Street, St. Louis, MO 63103. 2,5-DNT(CAS \# 619-15-8; lot\#15317-24; purity 99.3\%) and 3,5-DNT (CAS \# 618-85-9; lot\#15317-8; purity $99.8 \%$ ) were produced by SRI International, 333 Ravenswood Avenue, Menlo Park, CA 94025.

\subsubsection{Assay materials}

The positive control for the genotoxicity assays, ethylmethane sulfonate (EMS) (CAS\# 62-50-0, lot 1338043) was purchased from Sigma-Aldrich (St. Louis, MO). MicroFlow Plus Kits ${ }^{\circledR}$ (lots: anticoagulant 080811/080305 buffer 21022102/2102204, RNase 070906/080530, rat antibody 99554, platelet antibody 03952, DNA stain 080408/080919, positive control RP0408, negative control RN0408) were purchased from Litron Laboratories (Rochester, NY). CometAssay ${ }^{\circledR}$ kits (lots: lysis buffer 13782J7/17176L8, slides 14252M7/14816B8/16650J8/19771M9, LMagarose 14590A8/19423K9, SYBR Green 14537A8/16651J8, control cells 13633J7) were purchased from Trevigen, Inc. (Gaithersburg, MD). Additional chemicals: phosphate buffered saline (lot ATG32393), ethylenediaminetetraacetic acid (EDTA) (CAS\# 60-00-4, lot 1359870), sodium hydroxide (CAS\# 1310-73-2, lot 077K-18221), dimethyl sulfoxide (DMSO) (CAS\# 67-68-5, lot 083108), methanol (CAS\# 67-56-1, lot BO516227), and ethanol (CAS\# 64-17-5, lot 020K3658) were purchased from Sigma-Aldrich (St. Louis, MO).

\subsubsection{Test animals}

These in vivo genotoxicity assays were conducted as part of a study on the repeated dose toxicity of DNT isomers, the results of which are reported in detail elsewhere [20]. The study was conducted in two phases, testing three isomers in each phase. One hundred and twenty-six male Sprague-Dawley rats (43-45 days old 151-175 g) were obtained from Charles River Laboratories, Wilmington, MA for each phase. Male rats were selected for use due to their potential for greater sensitivity in these assays. The cancer bioassays indicated gender difference in the incidence of liver tumors [4]. Gender differences in metabolism and enterohepatic cycling also indicate that the amount of active metabolite produced by males is greater than that of females [18]. The Attending Veterinarian examined the animals and found them to be in acceptable health. The animals were acclimatized for 7 days upon arrival. For each phase, animals were randomly distributed using the LABCAT $^{\circledR}$ randomization program into six treatment groups per isomer and three control groups (corn oil control, negative control, and positive control) consisting of six rats each. Rats were distributed into groups according to body mass the day before the start of dosing. To facilitate scheduling of necropsies, the animals were then divided into six experimental start dates, with one animal from each treatment group per start date. The rats were seven weeks old and weighed $262 \pm 29.7$ and $260 \pm 17.9 \mathrm{~g}$ at the start of the study for phase I and II, respectively; body mass did not differ between treatment groups at the start of the study. Housing conditions were maintained at $64-79{ }^{\circ} \mathrm{F}$, $30 \%$ to $70 \%$ relative humidity with a 12 -h light/dark cycle. A certified pesticide-free rodent chow (Harlan Teklad ${ }^{\circledR}, 8728$ C Certified Rodent Diet) and drinking quality water were available ad libitum. Rats were housed individually in suspended polycarbonate boxes with Harlan Sani-Chip ${ }^{\circledR}$ bedding. All animal investigations were conducted in an American Association for the Accreditation of Laboratory Animal Care (AALAC) accredited facility with approval of the Institutional Animal Care and
Use Committee. Investigations were conducted in compliance with DOD and federal statutes and regulations pertaining to experiments involving animals and adhered to principles stated in the Guide for the Care and Use of Laboratory Animals [21].

\subsection{Methods}

\subsubsection{Test article administration}

Three solutions/suspensions in corn oil were prepared for each isomer and analyzed to verify concentration, homogeneity, and stability. The test articles were administered once daily for 14 days using a syringe attached to a 16 gauge gavage needle. Animals were euthanized the morning following administration of the final dose. A final dose was not administered 1-3 h prior to necropsy because this dose was deemed to be of little value given the complex metabolism of DNTs which requires more time to produce the active metabolite. Unlike other compounds which typically induce UDS after $1-2 \mathrm{~h}$, DNT induced UDS is delayed for $12 \mathrm{~h}[22,23]$, indicating that delayed sampling is appropriate for this compound. Dosing volume was calculated based on the most recent body mass measurement. The corn oil control group was given an equivalent volume as the highest dose group for each phase (6.9 and $9 \mathrm{ml} / \mathrm{kg}$, respectively). Dose levels were selected based on reported $\mathrm{LD}_{50}$ values and an acute range finding study; and were set at a maximum of $1 / 2$ or $1 / 4$ of the $\mathrm{LD}_{50}$. The test groups were as shown in Table 1.

A $60 \mathrm{mg} / \mathrm{ml}$ solution of ethylmethane sulfonate (EMS) in filtered water was prepared fresh each day for use as the positive control solution. This solution was used within one hour of preparation. EMS was administered at a dose of $200 \mathrm{mg} / \mathrm{kg}$ based on daily rat mass and volume of solution. Each positive control animal was orally dosed approximately 24 and $4 \mathrm{~h}$ prior to being euthanized.

\subsubsection{Peripheral blood micronucleus assay}

The micronucleus assay was conducted on peripheral blood from the top three surviving dose groups for each isomer (see Table 1) and the control groups using the MicroFlow Plus Kit ${ }^{\circledR}$ (Litron Laboratories, Rochester, NY) following the manufacturer's instructions [24]. Briefly, approximately $120 \mu \mathrm{l}$ of peripheral blood was collected on the day of necropsy from the saphenous vein by puncturing the vein with an 18 gauge needle. The blood was collected using a pipette with a tip precoated in anti-coagulant. The blood was placed in a microcentrifuge tube containing $0.35 \mathrm{ml}$ of anticoagulant and stored at $4-6{ }^{\circ} \mathrm{C}$ prior to fixing. The blood/anticoagulant was fixed by rapidly pipetting $180 \mu \mathrm{l}$ of blood/anticoagulant into centrifuge tubes containing $2 \mathrm{ml}$ of methanol at $-80^{\circ} \mathrm{C}$, vortexing briefly, and returning to -75 to $-85^{\circ} \mathrm{C}$ for storage until analysis. On the day of analysis by flow cytometry, the blood samples were washed out of fixative, treated with RNase A, surface marker antibodies conjugated with fluorescein isothiocyanate (FITC) and phycoerythrin (PE), and a DNA staining solution (propidium iodide, PI) to dye micronuclei. Anti-CD71FITC antibodies were used to distinguish mature erythrocytes (CD71-negative) from reticulocytes (CD71-positive), while PI was used to detect cells with DNA. Antiplatelet-PE was used to detect and remove platelets from the analysis. Therefore, the population of interest, micronucleated recticulocytes (MN-RET), was identified as those cells having high levels of both CD71-FITC and PI-associated fluorescence. Prior to analysis of samples, the flow cytometer (Coulter Epics XL/MCL; Beckman Coulter, Miami, FL) was set-up and calibrated using the kit provided standards. AntiCD71, anti-platelet-PE and PI fluorescence signals were detected in the FL1, FL2 and FL3 channels, respectively. A total of 20,000 MN-RETs were analyzed per sample. The data collected from the micronucleus assay were expressed as the percentage of reticulocytes with micronuclei (\%MN-RET). The percent of recticulocytes (\%RET) was also calculated as an indicator of effects on hematopoiesis.

\subsubsection{Comet assay}

The Comet assay was used to assess DNA damage in liver cells from rats in the top three surviving treatment groups for each isomer (see Table 1) and control rats using the CometAssay ${ }^{\circledR}$ kit from Trevigen (Gaithersburg, MD). To create a single cell suspension of liver cells, a small portion (1-2g) of the left lateral lobe of the liver was removed, rinsed with ice-cold mincing buffer (1X PBS, 20 mM EDTA) and finely minced. The minced tissue was then pressed through a $70 \mu \mathrm{m}$ cell sieve and the suspension washed twice to remove residual blood and cellular debris by centrifuging at $55 \times \mathrm{g}$ for $5 \mathrm{~min}$ at $4^{\circ} \mathrm{C}$. The pellet was re-suspended in $1 \mathrm{X}$ PBS for use in the assay. The assay was performed according to the manufacturer's instructions. Briefly, following isolation the cell suspension was mixed with low melting temperature agarose at a ratio of $1: 10(\mathrm{v} / \mathrm{v})$ and pipetted onto the commercially prepared slides. Slides were placed flat at $4{ }^{\circ} \mathrm{C}$ in the dark for $30 \mathrm{~min}$. Slides were then placed in pre-chilled Lysis Solution at $4{ }^{\circ} \mathrm{C}$ for $60 \mathrm{~min}$. Slides were then immersed in freshly prepared Alkaline Unwinding Solution for $60 \mathrm{~min}$ at room temperature in the dark. Slides were then transferred to a horizontal electrophoresis apparatus and electrophoresed for $60 \mathrm{~min}$ at $0.7 \mathrm{~V} / \mathrm{cm}, 296-300 \mathrm{mAmps}$ at $4-8^{\circ} \mathrm{C}$. After removal from the electrophoresis tank, the slides were rinsed in distilled water, immersed in $70 \%$ ethanol for $5 \mathrm{~min}$ and dried on a slide warmer at $37^{\circ} \mathrm{C}$. Slides were stained with SYBR green and visualized using an epifluorescence microscope (Olympus BH-2). To quantify the amount of DNA damage, 75 cells from each slide ( 2 slides per animal) were read using DNA damage analysis software (CometScore, TriTek Corp., Sumerduk, VA). To quantify DNA damage percent tail DNA (TDNA) and Olive tail moment (OTM) were measured. 
Table 1

Summary of study design.

\begin{tabular}{|c|c|c|c|c|c|c|}
\hline Isomer & Study phase & Dose group (mg/kg-day) & Dose concentration $(\mathrm{mg} / \mathrm{ml})$ & Dosing volume (ml/kg) & Survival & Dose group selected for use in assays \\
\hline \multirow[t]{6}{*}{ 2,3-DNT } & I & 17 & 5 & 3.4 & $6 / 6$ & \\
\hline & & 34 & 5 & 6.9 & $6 / 6$ & \\
\hline & & 69 & 20 & 3.4 & $6 / 6$ & $*$ \\
\hline & & 138 & 20 & 6.9 & $6 / 6$ & $*$ \\
\hline & & 275 & 80 & 3.4 & $6 / 6$ & $*$ \\
\hline & & 550 & 80 & 6.9 & $0 / 6$ & NA \\
\hline \multirow[t]{6}{*}{ 3,4-DNT } & I & 7 & 2 & 3.4 & $6 / 6$ & \\
\hline & & 14 & 2 & 6.9 & $6 / 6$ & \\
\hline & & 28 & 8 & 3.4 & $6 / 6$ & \\
\hline & & 57 & 8 & 6.9 & $6 / 6$ & $*$ \\
\hline & & 113 & 32 & 3.4 & $6 / 6$ & $*$ \\
\hline & & 227 & 32 & 6.9 & $6 / 6$ & $*$ \\
\hline \multirow[t]{6}{*}{ 2,6-DNT } & I & 4 & 2 & 3.4 & $6 / 6$ & \\
\hline & & 7 & 2 & 6.9 & $6 / 6$ & \\
\hline & & 14 & 7 & 3.4 & $6 / 6$ & \\
\hline & & 35 & 7 & 6.9 & $6 / 6$ & $*$ \\
\hline & & 68 & 32 & 3.4 & $6 / 6$ & $*$ \\
\hline & & 134 & 32 & 6.9 & $6 / 6$ & $*$ \\
\hline \multirow[t]{6}{*}{ 2,4-DNT } & II & 9 & 2 & 4.5 & $6 / 6$ & \\
\hline & & 18 & 2 & 9.0 & $6 / 6$ & \\
\hline & & 36 & 8 & 4.5 & $6 / 6$ & $*$ \\
\hline & & 71 & 8 & 9.0 & $6 / 6$ & $*$ \\
\hline & & 142 & 32 & 4.5 & $6 / 6$ & $*$ \\
\hline & & 284 & 32 & 9.0 & $0 / 6$ & NA \\
\hline \multirow[t]{6}{*}{ 2,5-DNT } & II & 10 & 2.5 & 4.5 & $6 / 6$ & \\
\hline & & 19 & 2.5 & 9.0 & $6 / 6$ & \\
\hline & & 39 & 10 & 4.5 & $6 / 6$ & \\
\hline & & 77 & 10 & 9.0 & $6 / 6$ & $*$ \\
\hline & & 154 & 40 & 4.5 & $6 / 6$ & $*$ \\
\hline & & 308 & 40 & 9.0 & $5 / 6$ & $*$ \\
\hline \multirow[t]{6}{*}{ 3,5-DNT } & II & 5 & 2 & 4.5 & $6 / 6$ & \\
\hline & & 10 & 2 & 9.0 & $6 / 6$ & $*$ \\
\hline & & 19 & 8 & 4.5 & $6 / 6$ & $*$ \\
\hline & & 39 & 8 & 9.0 & $5 / 6$ & $*$ \\
\hline & & 77 & 32 & 4.5 & $0 / 6$ & NA \\
\hline & & 155 & 32 & 9.0 & $0 / 6$ & NA \\
\hline
\end{tabular}

2.2.4. Liver histopathology

Tissues were collected and appropriately preserved in 10\% buffered formalin, packaged and shipped to Comparative Biosciences, Inc (Sunnyvale, CA) for processing. Cassettes containing tissues were processed through a graded series of alcohols using an automated processor, then oriented and embedded in paraffin, sectioned at approximately 3-5 $\mu \mathrm{m}$ thickness, stained with hematoxylin and eosin and coverslipped. Evaluation of liver tissue for all dose groups and controls used in the Comet assay was performed by an American College of Veterinary Pathology board certified military veterinary pathologist. The severities of lesions per tissue were recorded as: Grade $0=$ normal, Grade $1=$ minimal $/$ trace, Grade $2=$ mild, Grade $3=$ moderate, Grade 4 = severe.

\subsubsection{Statistical analyses}

Results are presented as animal means \pm standard error of the mean (SEM) for each treatment group. For parameters with multiple samples or measurements per animal, sample means were calculated prior to analysis and all analyses were conducted on the animal means of the sample means such that the animal was treated as the experimental unit for all analyses. Statistical analyses were performed using SPSS ${ }^{\circledR} 16.0$ software. One-way analysis of variance (ANOVA) was used to test for differences among treated and control groups within each phase. If the ANOVA showed significant differences, post hoc analysis was conducted using a Tukey's multiple comparison tests. Statistical significance was defined as $P<0.05$.

\section{Results}

\subsection{Mortality and clinical observations}

Mortality occurred in all animals administered 2,3-DNT at $550 \mathrm{mg} / \mathrm{kg}$-day after 2-4 days of dosing. Clinical signs of toxicity, including cyanosis, lethargy, squinting, rapid respiration/labored breathing, hunched posture, dark urine, and chromodacryorrhea, and were observed in the $550 \mathrm{mg} / \mathrm{kg}$-day dose group. Due to the mortality in the $550 \mathrm{mg} / \mathrm{kg}$-day group, the $275 \mathrm{mg} / \mathrm{kg}$-day dose was the highest dose used in the genotoxicity assays as it was the maximum tolerated dose (MTD) for 14-days.

Clinical signs of toxicity, including cyanosis, lethargy, dark urine, facial twitching, and hypoactivity/staring were observed in rats administered 3,4-DNT at $227 \mathrm{mg} / \mathrm{kg}$-day. Dark urine was observed in the $113 \mathrm{mg} / \mathrm{kg}$-day group.

No overt clinical signs of toxicity were observed in any 2,6-DNT dose groups. Dark urine and dried red material around nose were observed in animals in the $134 \mathrm{mg} / \mathrm{kg}$-day group.

Mortality occurred in all animals dosed with 2,4-DNT at $284 \mathrm{mg} / \mathrm{kg}$-day after 2-7 days of dosing. Clinical signs of toxicity, including cyanosis, squinting, lethargy, prostrate posture, rapid respiration/labored breathing, hunched posture, dark urine, red discharge around nose/dried red material around nose, and orange feces, limb paralysis were observed in the $284 \mathrm{mg} / \mathrm{kg}$-day dose group. Observations in lower dose groups were limited to dried red material around nose and barbering.

Clinical signs of toxicity, including cyanosis, squinting, prostrate posture, rapid respiration/labored breathing, hunched posture, dark urine, red discharge around nose/dried red material around nose, orange feces, and soft feces or diarrhea were observed in the 154 and $308 \mathrm{mg} / \mathrm{kg}$-day 2,5-DNT dose groups. Observations in lower dose groups were primarily limited to dried red material around nose, and barbering.

Mortality occurred in all animals dosed with 3,5-DNT at 77 and $155 \mathrm{mg} / \mathrm{kg}$-day after approximately 8 and 4 days of dosing, respectively. Clinical signs of toxicity, including cyanosis, squinting, prostrate posture, rapid respiration/labored breathing, hunched 
posture, dark urine, red discharge around nose/dried red material around nose, and orange feces were observed in the 77 and/or $155 \mathrm{mg} / \mathrm{kg}$-day dose groups. In addition, animals in the 39,77 , and $155 \mathrm{mg} / \mathrm{kg}$-day dose groups exhibited signs of neurological impairment that progressed rapidly from facial twitching, head bobbing, tilted head carriage, and uncoordinated movement, to loss of motor control, and paralysis of the thoracic limbs. Observations in lower dose groups were primarily limited to dried red material around nose, and barbering.

Due to mortality in the highest dose groups of 2,3-, 2,4-, and 3,5-DNT, lower dose groups were selected for use in the genotoxicity assays for these isomers (see Table 1 ). With the exception of 2,6-DNT, the pattern of mortalities and clinical signs indicate that the highest dose groups selected for use in the genotoxicity assays represent a 14-day maximum tolerated dose (MTD).

\subsection{Peripheral blood micronucleus assay}

For 2,5-DNT, distortion was observed in the flow cytometry data plots such that the NCE population pulled upward into the RET population, artificially increasing the frequency of MN-RET reported. Because the distortion increased in a dose-dependent manner, the effect was believed to be treatment related. Similar patterns of distortion have been observed with compounds that induce methemoglobinemia, suggesting that the pattern is autofluorescence associated with methemoglobinemia. As 2,5DNT induced severe cyanosis and anemia and DNTs have been reported to induce methemoglobinemia [3], the distortion in plots for 2,5-DNT was likely due to autofluorescence associated with methemoglobinemia. Because the autofluorescence caused a dosedependent artificial increase in the frequency of MN-RET reported, post-acquisition adjustments were made to the gating parameters to accommodate for a modest degree of autofluorescence. To prevent NCEs with autofluorescence being incorrectly scored as RETs, the RET population was restricted to high CD71 positive RETs. Due to the high likelihood that all of the DNT isomers induce methemoglobinemia and observations of cyanosis, gating parameters adjusted to accommodate autofluorescence were used in the analysis for all data. The $308 \mathrm{mg} / \mathrm{kg}$-day group was dropped from analysis as the autofluorescence could not be corrected. Despite apparent correction of autofluorescence in the $154 \mathrm{mg} / \mathrm{kg}$ day 2,5-DNT group, there was a two fold increase $(P=0.025)$ in the frequency of MN-RET (Table 2). Treatment with 2,3-DNT, 3,4-DNT, 2,6-DNT, 2,4-DNT and 3,5-DNT did not increase the frequency of MN-RET relative to the concurrent corn oil control (Table 2). There were approximately 1.5 and 1.8 fold increases in MN-RET frequency in the highest doses of 2,4-DNT and 3,5-DNT, respectively; however, these increases were not statistically significant. Although a sample size of six would suggest sufficient power to detect approximately 2 fold differences in the flow cytometric assay, power was limited by inter-animal variability which ranged from 0.03 to 0.12 [25].

The percentage of reticulocytes (\%RET) was increased relative to the corn oil control group at the highest dose for 2,6-DNT $(P=0.002)$ and 2,4-DNT $(P<0.001)$ and was increased at all doses for 2,5 -DNT $(P<0.001)$ (Table 2$)$. Reticulocyte frequency did not change relative to the concurrent control group for 2,3-DNT, 3,4-DNT or 3,5-DNT.

\subsection{Comet assay}

For 2,6-DNT, TDNA and OTM were increased $(P<0.001$ and $P<0.001$, respectively) in all dose groups relative to the corn oil control group and both measures demonstrated a dose response such that DNA damage increased with increasing dose (Fig. 1). 2,6DNT doses of 35,68 , and $134 \mathrm{mg} / \mathrm{kg}$-day resulted in $2.89,3.38$, and 3.64 fold increases in TDNA values, respectively, relative to the concurrent corn oil control (Fig. 1, Table 3). TDNA did not differ significantly between treated groups and concurrent controls for the minor isomers, with fold increases ranging from 0.92 to 1.96 (Table 3). A 2.08 fold increase in TDNA was observed for 2,4-DNT, however, this difference was not statistically significant, possibly due to large animal to animal variability.

Table 2

Results of the rat peripheral blood micronucleus assay.

\begin{tabular}{|c|c|c|c|c|c|c|c|}
\hline \multirow[t]{2}{*}{ Study phase } & \multirow[t]{2}{*}{ Compound } & \multirow[t]{2}{*}{ Dose (mg/kg-day) } & \multirow[t]{2}{*}{$n$} & \multicolumn{2}{|c|}{ MN-RET (\%) } & \multicolumn{2}{|c|}{ RET (\%) } \\
\hline & & & & Mean & SEM & Mean & SEM \\
\hline \multirow[t]{10}{*}{ I } & Corn oil control & & 6 & 0.12 & 0.024 & 0.82 & 0.02 \\
\hline & 2,3-DNT & 69 & 6 & 0.12 & 0.033 & 0.78 & 0.17 \\
\hline & & 138 & 6 & 0.11 & 0.019 & 0.89 & 0.18 \\
\hline & & 275 & 6 & 0.12 & 0.019 & 0.98 & 0.21 \\
\hline & 2,6-DNT & 35 & 5 & 0.15 & 0.032 & 1.03 & 0.17 \\
\hline & & 68 & 5 & 0.15 & 0.041 & 0.92 & 0.41 \\
\hline & & 134 & 5 & 0.13 & 0.012 & $3.02^{*}$ & 0.74 \\
\hline & 3,4-DNT & 57 & 6 & 0.12 & 0.026 & 0.80 & 0.23 \\
\hline & & 113 & 6 & 0.09 & 0.003 & 1.11 & 0.23 \\
\hline & & 227 & 6 & 0.13 & 0.018 & 1.21 & 0.13 \\
\hline \multirow[t]{10}{*}{ II } & Corn oil control & & 6 & 0.12 & 0.019 & 0.96 & 0.16 \\
\hline & 2,4-DNT & 36 & 6 & 0.11 & 0.016 & 0.85 & 0.12 \\
\hline & & 71 & 6 & 0.12 & 0.016 & 1.09 & 0.20 \\
\hline & & 142 & 6 & 0.18 & 0.018 & $3.30^{*}$ & 0.45 \\
\hline & 2,5-DNT & 77 & 6 & 0.18 & 0.028 & 4.97 & 0.62 \\
\hline & & 154 & 6 & $0.24^{*}$ & $0.039^{*}$ & $6.89^{*}$ & 0.75 \\
\hline & & 308 & 5 & & & $9.02^{*}$ & 1.52 \\
\hline & 3,5-DNT & 10 & 6 & 0.10 & 0.016 & 1.17 & 0.23 \\
\hline & & 19 & 6 & 0.10 & 0.012 & 1.88 & 0.33 \\
\hline & & 39 & 6 & 0.21 & 0.050 & 0.82 & 0.36 \\
\hline
\end{tabular}

MN-RET (\%): percent micronucleated reticulocytes, RET (\%): percent reticulocytes.

${ }^{*} P<0.05$. 


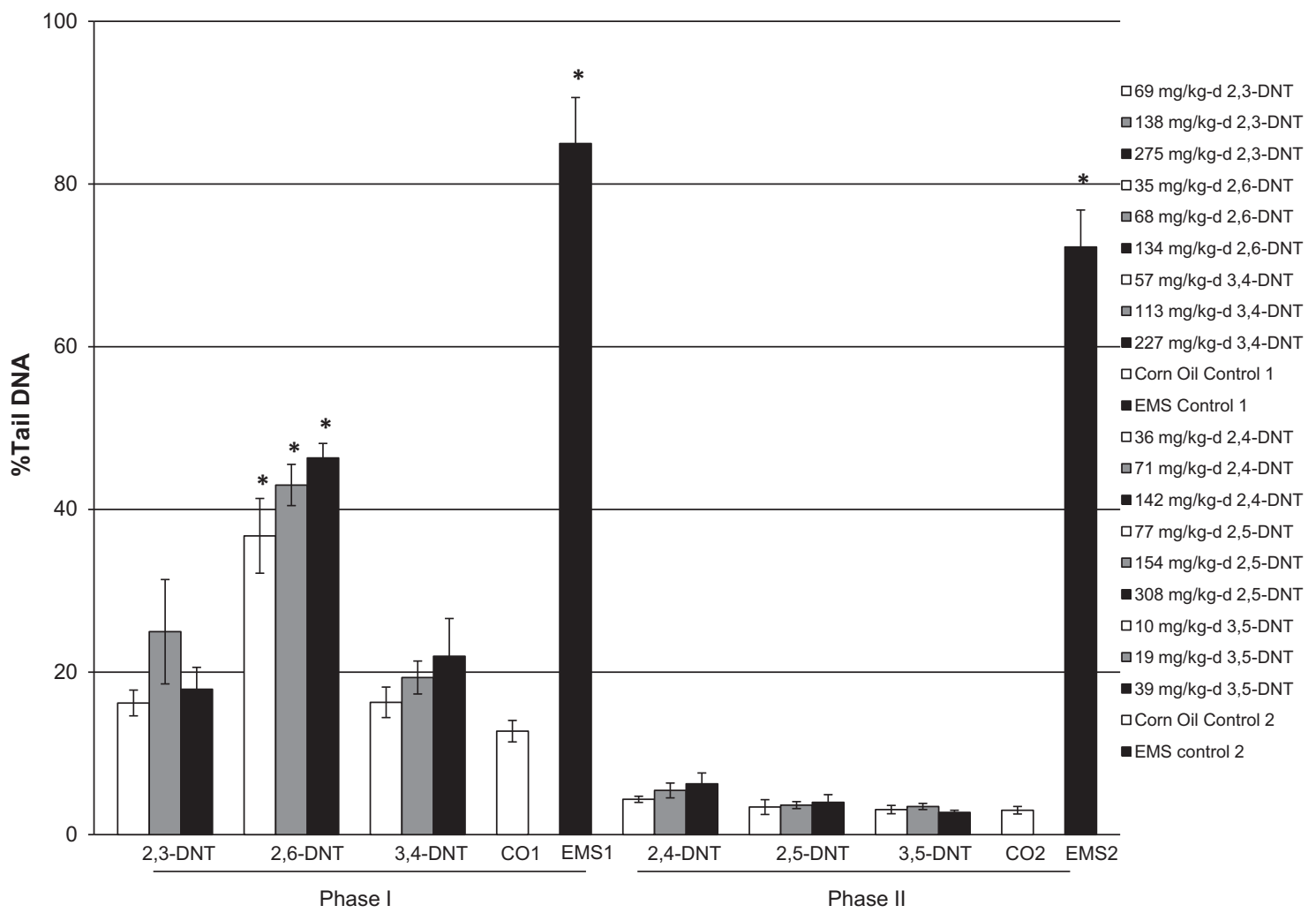

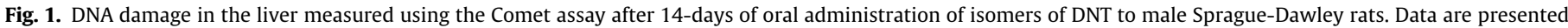

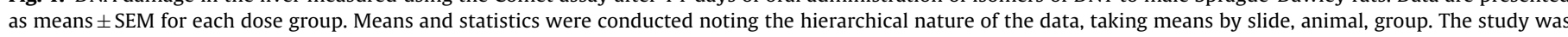

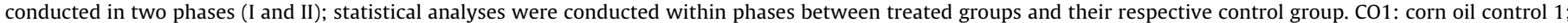
CO2: corn oil control 2; EMS 1: ethylmethane sulfonate 1 (positive control); EMS 2: ethylmethane sulfonate 2 (positive control). ${ }^{*} P<0.05$.

Table 3

Results of the in vivo liver Comet assay.

\begin{tabular}{|c|c|c|c|c|c|c|c|c|}
\hline \multirow[t]{2}{*}{ Study phase } & \multirow[t]{2}{*}{ Compound } & \multirow[t]{2}{*}{ Dose (mg/kg-day) } & \multirow[t]{2}{*}{$n$} & \multicolumn{2}{|l|}{ TDNA } & \multirow[t]{2}{*}{ Fold increase } & \multicolumn{2}{|l|}{ OTM } \\
\hline & & & & Mean & SEM & & Mean & SEM \\
\hline \multirow[t]{11}{*}{ I } & Corn Oil Control & & 6 & 12.73 & 1.32 & & 6.81 & 0.80 \\
\hline & EMS Control & 200 & 6 & 84.99 & 5.65 & 6.68 & $96.48^{*}$ & 14.99 \\
\hline & 2,3-DNT & 69 & 6 & 16.20 & 1.58 & 1.27 & 8.39 & 0.63 \\
\hline & & 138 & 6 & 24.96 & 6.42 & 1.96 & 21.32 & 10.55 \\
\hline & & 275 & 6 & 17.88 & 2.70 & 1.40 & 11.35 & 2.74 \\
\hline & 2,6-DNT & 35 & 6 & 36.75 & 4.59 & 2.89 & 32.08 & 5.15 \\
\hline & & 68 & 6 & 43.00 & 2.53 & 3.38 & 38.86 & 6.03 \\
\hline & & 134 & 6 & 46.32 & 1.79 & 3.64 & 44.32 & 4.40 \\
\hline & 3,4-DNT & 57 & 6 & 16.28 & 1.88 & 1.28 & 9.29 & 1.33 \\
\hline & & 113 & 6 & 19.33 & 2.03 & 1.52 & 12.59 & 1.66 \\
\hline & & 227 & 6 & 21.96 & 4.63 & 1.73 & 17.00 & 6.29 \\
\hline \multirow[t]{11}{*}{ II } & Corn Oil Control & & 6 & 3.01 & 0.46 & & 2.16 & 0.35 \\
\hline & EMS Control & 200 & 6 & $72.27^{*}$ & 4.54 & 24.01 & $68.22^{*}$ & 4.63 \\
\hline & 2,4-DNT & 36 & 6 & 4.35 & 0.38 & 1.45 & 3.21 & 0.30 \\
\hline & & 71 & 6 & 5.44 & 0.91 & 1.81 & 4.34 & 0.81 \\
\hline & & 142 & 6 & 6.25 & 1.34 & 2.08 & 5.03 & 1.25 \\
\hline & 2,5-DNT & 77 & 6 & 3.40 & 0.91 & 1.13 & 2.63 & 0.75 \\
\hline & & 154 & 5 & 3.64 & 0.43 & 1.21 & 2.74 & 0.35 \\
\hline & & 308 & 6 & 3.97 & 0.95 & 1.32 & 3.23 & 0.75 \\
\hline & 3,5-DNT & 10 & 6 & 3.09 & 0.63 & 1.03 & 2.32 & 0.51 \\
\hline & & 19 & 6 & 3.47 & 0.44 & 1.15 & 2.54 & 0.38 \\
\hline & & 39 & 6 & 2.76 & 0.41 & 0.92 & 1.85 & 0.25 \\
\hline
\end{tabular}




\subsection{Liver cytotoxicity}

2,6-DNT showed moderate single cell necrosis in 5/6 rats in each of the 68 and $134 \mathrm{mg} / \mathrm{kg}$-day dose groups. For 2,4-DNT, trace to mild single cell necrosis was noted in $3 / 6$ at $36 \mathrm{mg} / \mathrm{kg}$-day, $1 / 6$ at $71 \mathrm{mg} / \mathrm{kg}$-day, and $4 / 6$ at $142 \mathrm{mg} / \mathrm{kg}$-day. Trace apoptosis was noted in $1 / 6$ rats in each of the 36 and $71 \mathrm{mg} / \mathrm{kg}$-day of 2,4-DNT dose groups. No treatment related liver toxicity was noted in the 2,3-DNT, 3,4-DNT, 2,5-DNT, or 3,5-DNT dose groups used in the micronucleus or Comet assays.

\section{Discussion}

This study, the first in vivo genotoxicity assessment for the minor isomers, demonstrated that treatment with the minor isomers (2,3-DNT, 3,4-DNT, 2,5-DNT, 3,5-DNT) did not induce DNA damage in liver cells or increase the frequency of MN-RET in the peripheral blood of treated rats. These results indicate that the minor isomers are not genotoxic at the doses tested. The major isomers, 2,4- and 2,6-DNT, have been the subject of more testing than the minor isomers. As in the in the present study, the major isomers have previously given negative results in the bone marrow or peripheral blood micronucleus assays [26-29]. The negative results in the peripheral blood micronucleus assay suggest that the active metabolites of DNT, produced through enterohepatic circulation $[18,19]$, did not reach the bone marrow. Active metabolites produced in the liver are often short lived and the concentration reaching the bone marrow does not allow for sufficient exposure to induce $\mathrm{MN}[28,30]$. Active metabolites produced in the liver may also be bound to liver tissue [18], never entering systemic circulation. It may also be that the bone marrow is not a target organ for DNTs. The hematological effects of several isomers, including increased \%RET; however, indicate that the bone marrow is a target organ. The effects on the hematopoietic system may, however, be due to the parent compound.

Many of the effects of dinitrotoluenes on the hematopoietic system are associated with the induction of methemoglobinemia [3]. Although it did not pose a problem in tests conducted with 2,4,6-trinitrotoluene (TNT) which gave clearly negative results, methemoglobinemia has been cited as a contributor to false positive results in micronucleus assays [31-33]. Two types of methemoglobinemia-associated false positive results occur in flow cytometry assays: an artificial increase in MN-RET counts measured by flow cytometry due to autofluorescence; and an actual, though non-genotoxic, increase in MN-RET that is due to disturbance of erythropoiesis. In the former, fluorescence associated with porphyrins and bilirubin resulting from methemoglobinemia related hemolysis may disrupt micronucleus assays. This type of methemoglobinemia associated fluorescence was observed in the present study; however, post-acquisition adjustments were made to gating parameters to reduce or eliminate the contribution of this fluorescence to detection of micronuclei. In the latter, the increases in MN-RET are due to reticulocytosis resulting from methemoglobinemia associated hemolysis. The increase in production of RETs possibly resulting from tissue hypoxia induced stimulation of erythropoietin secretion [33]. Accelerated proliferation and differentiation of erythrocytes can lead to increased MN-RETs due to more opportunities for spontaneous errors in cell division and errors during enucleation [32,33]. Stimulation of erythropoiesis by erythropoietin may also reduce the efficiency of DNA repair and, through the suppression of apoptosis, possibly enable the survival of damaged cells [34,35]. Treatment with erythropoietin and stimulation of erythropoiesis has been shown in mice to increase micronuclei frequency, theoretically as a result of reduced efficiency of DNA repair [32]. In the case of aniline, however, the compound did not exhibit in vivo clastogenic activity in the mouse bone marrow, suggesting a non-genotoxic origin for the observed micronuclei [32]. In the present study, several isomers (2,6-DNT, 2,4-DNT, 2,5-DNT) demonstrate increases in reticulocytes, while only 2,5-DNT has apparent, though likely false, increases in micronuclei. As with aniline, the response observed in the micronucleus assay is likely due to disruption of erythropoiesis rather than genotoxicity.

DNA damage was detected in liver cells using the Comet assay following in vivo administration of 2,6-DNT, but not 2,4-DNT. The results are in agreement with recent work which showed an increase in the incidence on micronucleated hepatocytes following a single dose of 2,6-DNT as low as $50 \mathrm{mg} / \mathrm{kg}$ or repeated doses as low as $33 \mathrm{mg} / \mathrm{kg}$-day [27-29]. In contrast to the current study, previous reports indicated that 2,4-DNT is genotoxic in the rat liver micronucleus assay at $200 \mathrm{mg} / \mathrm{kg}$ [28]. The discrepant results for 2,4-DNT may be due to differences in doses used ( $142 \mathrm{mg} / \mathrm{kg}$-day vs. $200 \mathrm{mg} / \mathrm{kg}$ ), strain differences [30], or differences in the types of damage detected [36]. The negative result for 2,4-DNT is supported by in vivo hepatocyte initiation-promotion assays in which 2,4-DNT demonstrated no initiating activity and the only carcinogenesis study conducted with pure 2,4-DNT in which 2,4-DNT did not induce hepatocarcinomas [6-9].

The necrosis associated with 2,4-DNT and 2,6-DNT may have confounded the results as excessive cytotoxicity and necrosis have been implicated in false positive results in the in vitro Comet assay [37]. Recent work has, however, suggested that, at least in the liver, tissue cytotoxicity does not lead to increased DNA migration in the in vivo Comet assay [29,38]. Additionally, work by Rothfuss et al. [29] demonstrated an increase in DNA damage in the in vivo liver Comet assay for rats exposed to $100 \mathrm{mg} / \mathrm{kg}$-day of 2,6-DNT for 3 days or $33 \mathrm{mg} / \mathrm{kg}$-day for 29 days $[28,29]$. Thus, the positive result for 2,6-DNT in the current study appears reliable despite cytotoxicity in two of the doses used. Cytotoxicity and necrosis have also been reported to cause a decrease in DNA migration if cells are collected in advanced stages of necrosis, resulting in false negatives [39]. Although necrosis was noted in all doses for 2,4-DNT, the finding was trace to mild and there was no increase in serum liver enzymes in any dose group [20]. In addition, for both 2,4-DNT and 2,6-DNT, the data exhibited a unimodal response with all cells showing similar levels of DNA migration rather than a bimodal distribution expected with necrosis [37]. Therefore, the hepatotoxicity of 2,4-DNT and 2,6-DNT did not give misleading results in the in vivo Comet assay.

These data support a body of research indicating that 2,6DNT was responsible for the hepatocarcinogenicity observed in studies using TG-DNT and mixtures of 2,4-DNT and 2,6-DNT e.g. $[6-9,18,19]$. Much of that work focused on the major isomers, demonstrating that 2,6-DNT, unlike 2,4-DNT, is a complete carcinogen and causes hepatocellular carcinomas [6-9]. In the only studies investigating the role of all the individual isomers, 2,4-DNT and the minor isomers were shown to have no detectable hepatocyte initiating activity [6]. The negative results for the minor isomers in the current study indicate that the minor isomers are not genotoxic, adding to the weight of evidence indicating that the carcinogenicity of TG-DNT is attributable to the 2,6-DNT isomer.

\section{Conflict of interest statement}

The authors declare that there are no conflicts of interest.

\section{Acknowledgements}

This work was funded by the U.S. Army Environmental Center Installation Restoration Program. The authors gratefully acknowledge the following people for the assistance: Matt Bazar, Patricia 
Beall, Shenell Bolden, LTC Kenneth Despain, Mike Hable, Terry Hanna, John Houpt, Craig McFarland, Will McCain, Curtis Oliver, Arthur O'Neill, and Mark Way.

\section{References}

[1] J.C. Pennington, T.F. Jenkins, G. Ampleman, S. Thiboutot, J.M. Brannon, J. Lewis, J.E. Delaney, J. Clausen, A.D. Hewitt, M.A. Hollander, C.A. Hayes, J.A. Stark, A. Marois, S. Brochu, H.Q. Dinh, D. Lambert, A. Gagnon, M. Bouchard, R. Martel, P. Brousseau, T.A. Ranney, C. Gauthier, S. Taylor, and J.M. Ballard Distribution and fate of energetic on DoD test and training ranges: Interim Report 3. US Army Engineer Research and Development Center, Vicksburg, Mississippi, Technical Report ERDC TR-03-2, 2004.

[2] E.P. Burrows, D.H. Rosenblatt, W.R. Mitchell, D.L. Parmer, Organic explosives and related compounds: environmental and health considerations. Technical Report 8901. U.S. Army Biomedical Research and Development Laboratory, Fort Detrick, Frederick, MD, 1989.

[3] H.V. Ellis III, J.H. Hagensen, J.R. Hodgson, J.L. Minor, C.-B. Hong, E.R. Ellis, J.D. Girvin, D.O. Helton, B.L. Herndon, C.-C. Lee, Mammalian Toxicity of Munitions Compounds Phase III: Effects of Lifetime Exposure Part I: 2,4-Dinitrotoluene, Midwest Research Institute, Kansas City, MO, 1979, Supported by U.S. Army Medical Research and Development Command, Fort Detrick, Frederick, MD.

[4] Chemical Industry Institute of Toxicology (CIIT): 104-Week Chronic Toxicity Study in Rats - Dinitrotoluene. Final Report, Volume I of II. CIIT Docket No. 12362, Research Triangle Institute, Research Triangle Park, North Carolina, 1982.

[5] National Cancer Institute(NCI), Bioassay of 2,4-Dintrotoluene for Possible Carcinogenicity. Carcinogenesis Testing Program, Division of Cancer Cause and Prevention, National Cancer Institute/National Institute of Health, Bethesda, MD, 1978.

[6] J.A. Popp, T.B. Leonard, The use of in vivo hepatic initiation-promotion systems in understanding the hepatocarcinogenicity of technical grade dinitrotoluene, Toxicol. Pathol. 10 (1982) 190-196.

[7] T.B. Leonard, O. Lyght, J.A. Popp, Dinitrotoluene structure-dependent initiation of hepatocytes in vivo, Carcinogenesis 4 (1983) 1059-1061.

[8] T.B. Leonard, T. Adams, J.A. Popp, Dinitrotoluene isomer-specific enhancement of the gene expression of diethylnitrosamine-initiated hepatocyte foci, Carcinogenesis 7 (1986) 1797-1803.

[9] T.B. Leonard, M.E. Graichen, J.A. Popp, Dinitrotoluene isomer-specific hepatocarcinogenesis in F344 rats, J. Natl. Cancer Inst. 79 (1987) 1313-1319.

[10] D.B. Couch, P.F. Allen, D.J. Abernethy, The mutagenicity of dinitrotoluenes in Salmonella typhimurium, Mutat. Res. 90 (1981) 373-383.

[11] V.L. Dellarco, M.J. Prival, Mutagenicity of nitro compounds in Salmonella typhimurium in the presence of flavin mononucleotide in a preincubation assay, Environ. Mol. Mutagen. 13 (1989) 116-127.

[12] H.V. Ellis III, J.R. Hodgson, S.W. Hwang, L.M. Halpap, D.O. Helton, B.S. Anderson, D.L. VanGoethem, C.-C. Lee, Mammalian Toxicity of Munitions Compounds Phase I: Acute Oral Toxicity, Primary Skin and Eye Irritation, Dermal Sensitization, Disposition and Metabolism and Ames tests of Additional Compounds, Midwest Research Institute, Kansas City, MO, 1978, Supported by U.S. Army Medical Research and Development Command, Fort Detrick, Frederick, MD.

[13] R.J. Spanggord, K.E. Mortelmans, A.F. Griffin, V.F. Simmon, Mutagenicity in Salmonella typhimurium and structure-activity relationships of wastewater components emanating from the manufacture of trinitrotoluene, Environ. Mutagen. 4 (1982) 163-179.

[14] D.J. Abernethy, D.B.\#\#D.B. Couch, Cytotoxicity and mutagenicity of dinitrotoluenes in Chinese hamster ovary cells, Mutat. Res. 103 (1982) 53-59.

[15] I. Holen, S.O. Mikalsen, T. Sanner, Effects of dinitrotoluenes on morphological cell transformation and intercellular communication in Syrian hamster embryo cells, J. Toxicol. Environ. Health 29 (1990) 89-98.

[16] E. Bermudez, D. Tillery, B.E. Butterworth, The effect of 2,4-dinitrotoluene and isomers of dinitrotoluene on unscheduled DNA synthesis in primary rat hepatocytes, Environ. Mutagen. 1 (1979) 391-398.

[17] J.Ashby, R.W. Tennant, Chemical structure, Salmonella mutagenicity and extent of carcinogenicity as indicators of genotoxic carcinogenesis among 222 chemicals tested in rodents by the U.S. NCI/NTP, Mutat. Res. 204 (1988) 17-115.

[18] D.E. Rickert, R.M. Long, S. Krakowka, J.G. Dent, Metabolism and excretion of $2,4-\left({ }^{14} \mathrm{C}\right)$ dinitrotoluene in conventional and axenic Fischer-344 rats, Toxicol. Appl. Pharmacol. 59 (1981) 574-579.

[19] J.C. Mirsalis, T.E. Hamm, J.M. Sherrill Jr., B.E. Butterworth, Role of gut flora in the genotoxicity of dinitrotoluene, Nature 295 (1982) 322-323.
[20] E.M. Lent, L.C.B. Crouse, M.J. Quinn, Jr., S.M. Wallace Comparison of the repeated dose toxicity of isomers of dinitrotoluene, Int. J Toxicol., in press.

[21] National Research Council, Institute of Laboratory Animal Resources, Commission on Life Sciences, Guide for the Care and Use of Laboratory Animals, National Academy Press, Washington, DC, 1996.

[22] J.C. Mirsalis, B.E. Butterworth, Induction of unscheduled DNA synthesis in rat hepatocytes following in vivo treatment with dinitrotoluene, Carcinogenesis 3 (1982) 241-245.

[23] J.C. Mirsalis, C.K. Tyson, B.E. Butterworth, Detection of genotoxic carcinogens in the in vivo-in vitro hepatocyte DNA repair assay, Environ. Mutagen. 4 (1982) $553-562$.

[24] Litron Laboratories, Instruction Manual MicroFlow Micronucleus Analysis Kit, 2003.

[25] G.E. Kissling, S.D. Dertinger, M. Hayashi, J.T. MacGregor., Sensitivity of the erythrocyte micronucleus assay: dependence on number of cells scored and inter-animal variability, Mutat. Res. 634 (2007) 235-240.

[26] J.\#\#J. Ashby, B. Burlinson, P.A. Lefevre, J. Topham, Non-genotoxicity of 2,4,6trinitrotoluene (TNT) to the mouse bone marrow and the rat liver: implications for its carcinogenicity, Arch. Toxicol. 58 (1985) 14-19.

[27] H. Takasawa, H. Suzuki, I. Ogawa, Y. Shimada, K. Kobayashi, Y. Terashima, H. Matsumoto, C. Aruga, K. Oshida, R. Ohta, T. Imamura, A. Miyazaki, M. Kawabata, S. Minowa, M. Hayashi, Evaluation of a liver micronucleus assay in young rats (III): a study using nine hepatotoxicants by the Collaborative Study Group for the Micronucleus Test (CSGMT)/Japanese Environmental Mutagen Society (JEMS)-Mammalian Mutagenicity Study Group (MMS), Mutat. Res. 698 (2010) 30-37.

[28] H. Takasawa, H. Suzuki, I. Ogawa, Y. Shimada, K. Kobayashi, Y. Terashima, H. Matsumoto, K. Oshida, R. Ohta, T. Imamura, A. Miyazaki, M. Kawabata, S. Minowa, A. Maeda, M. Hayashi, Evaluation of a liver micronucleus assay in young rats (IV): a study using a double-dosing/single-sampling method by the Collaborative Study Group for the Micronucleus Test (CSGMT)/Japanese Environmental Mutagen Society (JEMS)-Mammalian Mutagenicity Study Group (MMS), Mutat. Res. 698 (2010) 24-29.

[29] A. Rothfuss, M. O’Donovan, M. De Boeck, D. Brault, A. Czich, L. Custer, S. Hamada, U. Plappert-Helbig, M. Hayashi, J. Howe, A.R. Kraynak, B.J. van der Leede, M Nakajima, C. Priestley, V. Thybaud, K. Saigo, S. Sawant, J. Shi, R. Storer, M. Struwe, E. Vock, S. Galloway, Collaborative study on fifteen compounds in the rat-liver Comet assay integrated into 2- and 4-week repeat-dose studies, Mutat. Res. 702 (2010) 40-69.

[30] H. Suzuki, H. Takasawa, K. Kobayashi, Y. Terashima, Y. Shimada, I. Ogawa, J. Tanaka, T. Imamura, A. Miyazaki, M. Hayashi, Evaluation of a liver micronucleus assay with 12 chemicals using young rats (II): a study by the Collaborative Study Group for the Micronucleus Test/Japanese Environmental Mutagen SocietyMammalian Mutagenicity Study Group, Mutagenesis 24 (2009) 9-16.

[31] J. Ashby, D.A. Vlachos, H. Tinwell, Activity of aniline in the mouse bone marrow micronucleus assay, Mutat. Res. 263 (1991) 115-117.

[32] E. Jones, V. Fox, Lack of clastogenic activity of aniline hydrochloride in the mouse bone marrow, Mutagenesis 18 (2003) 283-286.

[33] D.J. Tweats, D. Blakey, R.H. Heflich, A. Jacobs, S.D. Jacobsen, T. Morita, T. Nohmi, M.R. O’Donovan, Y.F. Sasaki, T. Sofuni, R. Tice, Report of the IWGT working group on strategies and interpretation of regulatory in vivo tests I. Increases in micronucleated bone marrow cells in rodents that do not indicate genotoxic hazards, Mutat. Res. 627 (2007) 78-91.

[34] Y. Suzuki, Y.Nagae, T. Ishikawa, Y. Watanabe, T. Nagashima, K. Matsukubo H. Shimizu, Effect of erythropoietin on the micronucleus test, Environ. Mol. Mutagen. 13 (1989) 314-318.

[35] M. Silva, D. Grillot, A. Benito, C. Richard, G. Nunez, J.L. Fernandez-Luna., Erythropoietin can promote erythroid progenitor survival by repressing apoptosis through Bcl-X and Bcl-2, Blood 88 (1996) 1576-1582.

[36] S. Kawaguchi, T. Nakamura, A. Yamamoto, G. Honda, Y.F. Sasaki, Is the Comet assay a sensitive procedure for detecting genotoxicity? J. Nucleic Acids 1 (2010) 541050.

[37] A. Hartmann, E. Agurell, C. Beevers, S. Brendler-Schwaab, B. Burlinson, P. Clay, A. Collins, A. Smith, G. Speit, V. Thybaud, R.R. Tice, Recommendations for conducting the in vivo alkaline Comet assay, Mutagenesis 18 (2003) 45-51.

[38] A. Rothfuss, M. Honma, A. Czich, M.J. Aardema, B. Burlinson, S. Galloway, S. Hamada, D. Kirkland, R.H. Heflich, J. Howe, M. Nakajima, M. O’Donovan, U. Plappert-Helbig, C. Priestley, L. Recio, M. Schuler, Y. Uno, H.J. Martus, Improvement of in vivo genotoxicity assessment: combination of acute tests and integration into standard toxicity testing, Mutat. Res. 723 (2011) 108-120.

[39] M.Z. Vasquez, Combining the in vivo Comet and micronucleus assays: a practical approach to genotoxicity testing and data interpretation, Mutagenesis 25 (2010) 187-199. 